\title{
QUALIFICATION OF THE CARBON DIOXIDE MEASUREMENT SYSTEM TO SUPERVISE AND IMPROVE THE PROCESS OF OBTAINING BREATHING GAS FOR OXYGEN HYPERBARIC CONDITIONS
}

\author{
Arkadiusz Woźniak \\ Department of Underwater Works Technology of the Polish Naval Academy, Gdynia, Poland
}

\begin{abstract}
Maintaining a stable carbon dioxide content below the established CTQ ${ }^{1}$ requirements in the process of obtaining breathing gas for hyperbaric oxygen conditions is essential for the safety of underwater work. This article discusses the subject of validation of a selected measuring system for on-line control of the breathing gas production process and describes the application of multidimensional sensory systems to control critical parameters of the production process in production systems intended for intensive use away from supply facilities. In this case, the on-line contamination measurement option should be considered ${ }^{2}$. Monitoring of the analysed process from the point of view of its ability to minimise its variability should be oriented towards measuring the input or process values in such a way as to prevent the occurrence of potential defects already at the production stage. The assessment of the CCS - Carbon Dioxide Control System ${ }^{3}$ selected for testing, designed to control the carbon dioxide content, was performed in DUWT PNA ${ }^{4}$ for the DGKN - 120 complex compressed air supply system ${ }^{5}$. The system evaluation was conducted using MSA $\mathrm{A}^{6}$ procedures and methods of SPC ${ }^{7}$. Keywords: breathing mixtures, measurement system, diving breathing air quality, measurement system analysis.
\end{abstract}

\section{ARTICLE INFO}

PolHypRes 2019 Vol. 69 Issue 4 pp. 7 - 32

ISSN: $1734-7009$ elSSN: 2084-0535

DOI: $10.2478 /$ phr-2019-0017

Pages: 26, figures: 11, tables: 1

page www of the periodical: www.phr.net.pl

Publisher

Polish Hyperbaric Medicine and Technology Society

\section{Original article}

Submission date: 22.02.2019 r.

Acceptance for print: 23.04.2019 r. 


\section{INTRODUCTION}

The primary objective of the project implemented in SZ RP, to date concerning rationalisation of obtained breathing air, maintenance and distribution intended for aerobic hyperbaric conditions, was to minimise the variability of the observed process and to maintain its stability over time. The rationalisation of the analysed production process was performed using SixSigma. The process rationalisation has sought to achieve a fixed overrun of the level $6 \sigma$. Observing the rationalised process of obtaining, maintaining and distributing breathing air admitted to aerobic hyperbaric conditions in the Polish Armed Forces, it has been noticed that with the currently available know-how, it is not possible to achieve such a level of process capacity for the entire analysed system [1].

The elimination of the identified risks for all subprocesses supporting the process of obtaining breathing air for hyperbaric purposes has contributed to a reduction in the number of non-compliances. The reduction in the number of non-compliances in terms $\mathrm{H}_{2} \mathrm{O}$ content was not accompanied by a proportionate reduction in the number of defects in terms of $\mathrm{CO}_{2}$ content. As presented in the process enhancement stage, the $\mathrm{CO}_{2}$ content in the entire tested population of measurement results after the initial decline returned to the previous level of about $20 \%$ of defects occurring in the years 2011-2012. As it was found as a result of the analysis, the occurrence of possible operator errors had a significant impact on meeting critical quality requirements CTQ. This indicates the limitations of the technology used so far.

It has been accepted that further improvement can only be achieved by changing the technology used. On the basis of the assessment, it has been concluded that for the systems used, there is a possibility of stable maintenance of the process capability at the level of $2.8 \sigma^{8}$. TheQuality Measures used in Approach $6 \sigma$ have been described earlier and will not be quoted here [1]. On the other hand, by following the technical solutions and descriptions of the know-how available on the market, it has been shown that achieving process capacity at appropriate level $4.5 \sigma$ [2] should be possible. The compression systems introduced have the potential to improve their efficiency, especially in terms of their resistance to potential operating errors and ongoing control of the supervised process. The results of the research conducted so far have led us to consider potential directions in which to take the production technology, especially in the area of elimination and control of the current $\mathrm{CO}_{2}$ content, e.g. through the use of pre-treatment filters of the substrate ${ }^{9}$ the issues of which will not be presented here combined with the use of multidimensional sensory systems to control critical process parameters ${ }^{10}$ of the production process.

This seems particularly important in production systems intended for intensive use away from supply facilities. In this case, consideration should be given to perform performance measurements for harmful contamination online ${ }^{11}$. As it has been already mentioned, monitoring of the process from the point of view of its ability to minimise its variability is to be oriented towards measuring the input or process values in such a way as to prevent the occurrence of potential defects already at the production stage. As a result of the research to date [1] the potential for short-term process capacity has been demonstrated. Research and risk analysis performed, such as $F M E A^{12}$ for a rationalised process, showed the need to increase the resistance of the systems to potentially occurring process disturbances caused by atmospheric pollution in the vicinity of compressor system inlet vents, and the lack of current control of process capacity.

To reduce the volume of work, many formulas are included in the text by moving batches of formulas between lines. The division of formulas occurred in places where operators of calculations were located in such a way that they occurred redundantly at the end of the previous and at the beginning of the next line.

\section{Problematic SituATion}

As a result of the work performed so far, directions for further industrial research have been proposed, and recommendations have been formulated concerning the supervision of a rationalised production process. Issues concerning the assessment of the influence of protective systems on the process of collecting, maintaining and distributing breathing gas intended for aerobic hyperbaric conditions are an important element of the production process. It has been shown that for the world's best technology currently used to obtain, maintain and distribute breathing air for aerobic hyperbaric conditions, the greatest potential is represented by protective systems, both in simple form ${ }^{13}$, and in the form of systems equipped with multidimensional sensory and expert systems and actuators ${ }^{14}[1]$.

The development of dedicated measurement systems to supervise and control the current production of breathing mixtures requires industrial research. The completed project [1] assumed that focusing on removing the $\mathrm{H}_{2} \mathrm{O}$ content from the breathing mixture would also result in a proportional reduction of other contaminants. The implementation of new purification and compression systems has confirmed this for all the contaminants concerned except for the $\mathrm{CO}_{2}$ content, which was lower than expected. Despite the actions taken to eliminate the disturbances of the process in question, the number of defects in the production process generated made it impossible to maintain a stable and capable process. The process risk assessment has shown that the use of measuring equipment for ongoing process control of critical parameters of carbon dioxide content is an important element in preventing defects. The use of threshold analytical indicators as shown in the analysis FMEA results via an increase in detection from incomplete $98 \%>D_{\%} \geq 90 \%$ to ideal $D_{\%} \cong 100 \%$ resulting in a decrease in the relative numerical probability of detection from $D=9$ to $D=1$. This entails a decrease in the relative value of the number of risks to an acceptable level $R P N=72[1]$

Substrate contamination, depletion of the purification filter element, failure of the room ventilation system, operating errors, among others, are a significant source of causes of defects in the production process under consideration. Proposed measuring systems should be used to control the process in a way that ensures that the measuring capacity is maintained in accordance with the requirements for measuring systems.

To conclude on the course of the process, it is necessary to correctly analyse and interpret the measurements made with the help of a capable 15 measuring systems. According to the PN-EN ISO 10012 
requirements, an effective measurement management system [3] should ensure their adaptation to the intended use and have a significant impact on the achievement of product and process ${ }^{16}$ and process quality ${ }^{17}$. Indicator analysis in combination with the warning indicator systems present in newer filtration systems ${ }^{18}$ allows for a limited number of simple process controls to be performed to eliminate errors and prevent contamination of the distribution systems. Process monitoring is focused on measuring input ${ }^{19}$ and process values ${ }^{20}$ that prevent the materialisation of risks arising from potential defects.

By current 21 monitoring 22 of the output parameter post factum, contamination of the distribution systems has been repeatedly identified. A barrier to the implementation of such solutions was the limitations resulting from the technical possibilities of such monitoring. Nowadays, specialised measuring systems have emerged on the market that can be used for this purpose, but due to their cost, it was decided to use them in the operation of high-performance breathing air production systems, supplying safety-critical distribution systems. Until now, in the case of compression system shut down, e.g. in the event of the exceeding of the carbon dioxide thresholds, the user, after repairing the system, performed independent operational measurements using portable analysers or other indicator devices, which were the basis for directing the sample for further laboratory tests.

Only after laboratory verification was it allowed for the system to be restarted. The introduction of adequate measurement systems for process monitoring will prevent the occurrence of defects, thus preventing the costly decommissioning of the compression system. In addition, it will reduce the costs of performing post-control laboratory analyses, provide an appropriate quality clause in the periods between the performance of the required laboratory periodic tests 23 and prevent contamination of 24 distribution systems or the penetration of foreign material 25 into storage systems. Importantly, it will prevent contamination caused by unexpected, premature shortening of filter life, which increases emissions, not only preventing the operation of the gas under hyperbaric oxygen conditions, but also causing contamination of the storage and distribution systems, which must later be cleaned before they can be allowed to enter the hyperbaric oxygen conditions again. The above situation occurring in the previous operating conditions, due to the lack of adequate protection systems, would have promoted the operation of an unknowingly faulty production system, until a periodical tests or random check of the quality of the breathing mixture performed by the system operator ${ }^{26}$ with the use of portable analysers.

Even the use of wear indicators, e.g. the control system SECURUS 27 installed in a part of the new filtering system sets, which by displaying an appropriate visual signal informs the operator of the saturation level of the filter elements, did not compensate for the existing danger. The collected measurement results of control samples of the hyperbaric systems in operation showed contamination of the storage and distribution systems [4], which may have occurred as a result of filter elements being perforated before the theoretical life of the filter elements had elapsed, or as a result of incorrectly prepared storage tanks, operating errors, $S O P$ non-observance etc. The use of an alarm indicator in compression and filtration systems in this case would prevent contamination of the marine installation.

\section{AIM OF THE WORK}

As shown by analysis of the context ${ }^{28}$ of the problem situation related to the process, the selection of a reliable and adequate monitoring and supervision system will eliminate some of the identified hazards, thus increasing the robustness of the compression and breathing air treatment systems to the occurrence of failures. Although the test-stand measurements performed $^{29}$ are less accurate than laboratory measurements, it is assumed that once the relevant metrological conditions are met and the measuring system is validated under operational conditions ${ }^{30}$ they will be accepted as sufficiently reliable to monitor and to make proposals for a rationalised process.

Taking into account the nature of the supervised process and minimising errors in measurements made by the operator, the assumption has been made to implement operational supervision in the form of monitoring performed automatically without the participation of the operator ${ }^{31}$. A fixed possibility of collecting measurement data with a specific sampling rate was assumed. It has been agreed that the measurement data of the carbon dioxide content would be analysed by means of check sheets ${ }^{32}$ and archived ${ }^{33}$. Methods of preparation and the selection of check sheets to rationalise the process have been omitted as they have already been described [5] [6]. The indicator control system is designed to prevent the process control limits being exceeded, thereby preventing contamination of the breathing mixture distribution system in ZTPP AMW intended for supplying $D G K N-120$. The main task of a measuring instrument selected for testing is to verify its functional correctness and to assess its metrological quality features [5] to supervise the rationalised ${ }^{34}$ production process.

\section{Tests, Material ANd Methodology}

The assessment of the measuring system selected $C C S^{35}$ for testing to control the carbon dioxide content has been performed for the compressed air supply system of the complex $D G K N-120^{36}$ in KTPPAMW ${ }^{37}$. In accordance with the quality control principles, the measuring system selected for testing had to be validated ${ }^{38}$. The assessment of metrological properties of the system was performed to qualify it to supervise the production of breathing air for divers. Table 1 presents basic descriptive statistics. 
Descriptive statistics for the carbon dioxide sensor of the CCS measuring system.

\begin{tabular}{lll} 
Statistics & $\begin{array}{l}\text { Measurement } \\
\text { value }\end{array}$ & Unit \\
\hline Number of valid measurements & 360 & - \\
\hline Mean & 201.02 & ppm \\
\hline Standard error of mean & 0.16 & ppm \\
\hline Standard deviation & 3.00 & ppm \\
\hline Modal value & 200 & ppm \\
\hline Minimum & 194 & ppm \\
\hline Maximum & 208 & ppm \\
\hline Median & 200 & ppm \\
\hline Skewness & 0.17 & - \\
\hline Kurtosis & -0.56 & - \\
\hline First quartile Q1 & 199 & $\mathrm{ppm}$ \\
\hline Third quartile Q3 & 203 & $\mathrm{ppm}$ \\
\hline Coefficient of variation & 1.49 & $\%$ \\
\hline
\end{tabular}

To identify the occurrence of the outlier (isolated) measurements ${ }^{39}$ in the group of $n=360$ performed measurements, Grubbs's Test has been applied. The null hypothesis has been verified $H_{0}$ - all measurement results come from the same population with a standard distribution relative to the alternative hypothesis $H_{1}$ - the lowest/greatest value is an outlier. The calculated value of the test function $G=2,34^{40}$, $(p-$ value $=1)$. Therefore, at the materiality level $\alpha=$ 0.05 there are no grounds to reject the hypothesis $H_{0} 41$.

The maximum absolute assessment error representing half the width of the confidence interval for the level is presented below $(1-\alpha=0.95)$ Fig. 1 .

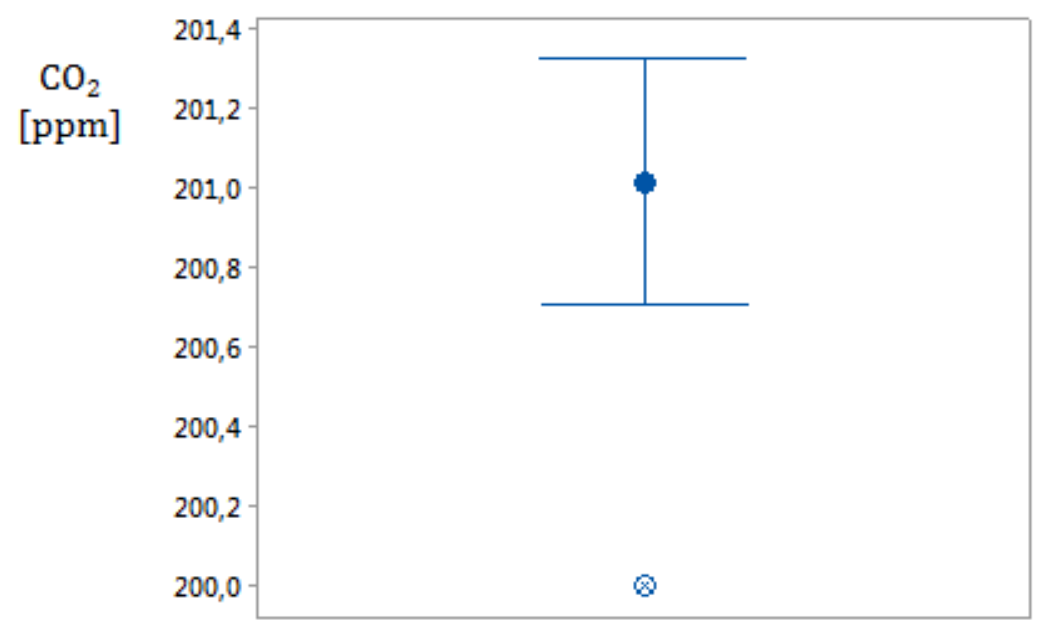

Fig. 1 Mean $x \pm \Delta x(1-\alpha=0.95)=201.02 \pm 0.30 p p m$ for fundamental standard 『CO $\_2$ measurements. Source: own research.

The calculated average measurement value $\bar{x}=$ $201,02 p p m$ is very close to the nominal value. The modal value is $C_{\mathrm{CO}_{2}}=200 \mathrm{ppm}$, this corresponds to the reference value of the fundamental standard used. The skewness $S K=0.17>0$ and the kurtosis value $K U=-0.55$ do not indicate any significant deviation from standard distribution. The median corresponds to the value of modal value (modes). Empirical distribution of fundamental standard measurement data including with confidence intervals for $\bar{x}$ and Me and $n=360$ are shown in Fig. 2. 


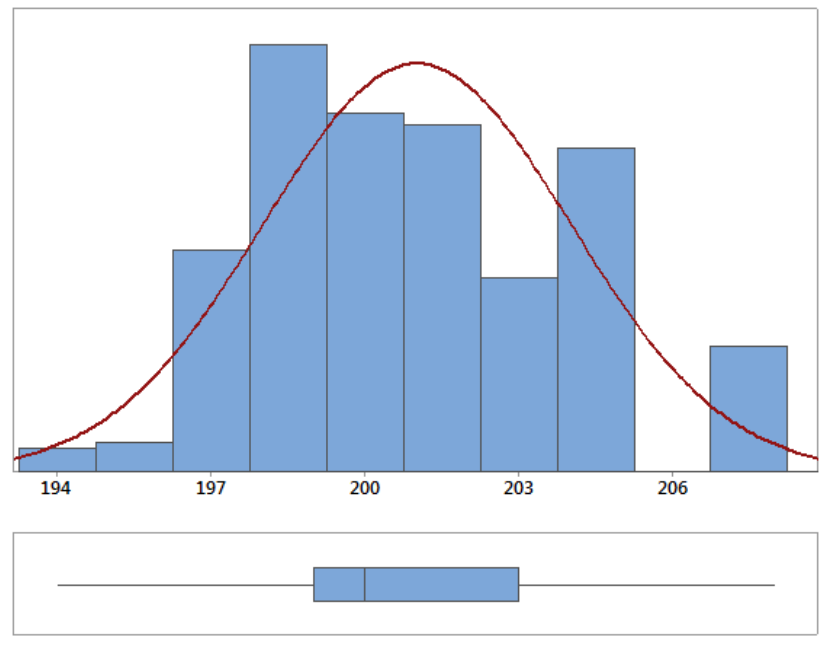

\begin{tabular}{|cc|}
\hline \multicolumn{3}{|c|}{ Anderson-Darling } & Normality Test \\
A-Squared & 4,51 \\
P-Value & $<0,005$ \\
\hline Mean & 201,02 \\
StDev & 3,00 \\
Variance & 9,02 \\
Skewness & 0,173743 \\
Kurtosis & $-0,557465$ \\
N & 360 \\
\hline Minimum & 194,00 \\
1st Quartile & 199,00 \\
Median & 200,00 \\
3rd Quartile & 203,00 \\
Maximum & 208,00 \\
\hline 95\% Confidence Interval for Mean \\
200,71 & 201,33 \\
95\% Confidence Interval for Median \\
200,00 & 202,00 \\
95\% Confidence Interval for StDev \\
2,80 \\
\multicolumn{2}{|c}{3,24} \\
\hline
\end{tabular}

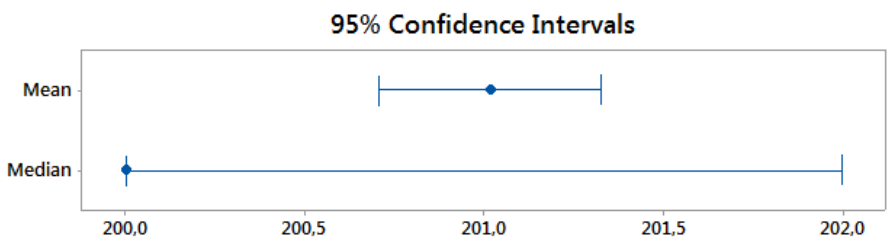

Fig. 2 Empirical and theoretical distribution of measurement data with confidence intervals for the mean and median (1- $\alpha=0.95)$. Source: own research.

The graphical test of normality for the measurement results confirms compliance with the standard distribution ${ }^{42}$ Fig. 3 . The presented so-called "clustered" 43 point system is characteristic for measuring systems and results from the resolving power of the analysed measuring device. This is the direct cause of the discrepancy in interpretation in terms of the value obtained $p-$ value $<0.005$ for the $A-D$ (AndersonDarling Test). The data distribution confirms that the resolution condition is met, indicating the possibility of distinguishing at least 10 parameter maintenance states in terms of its variability.

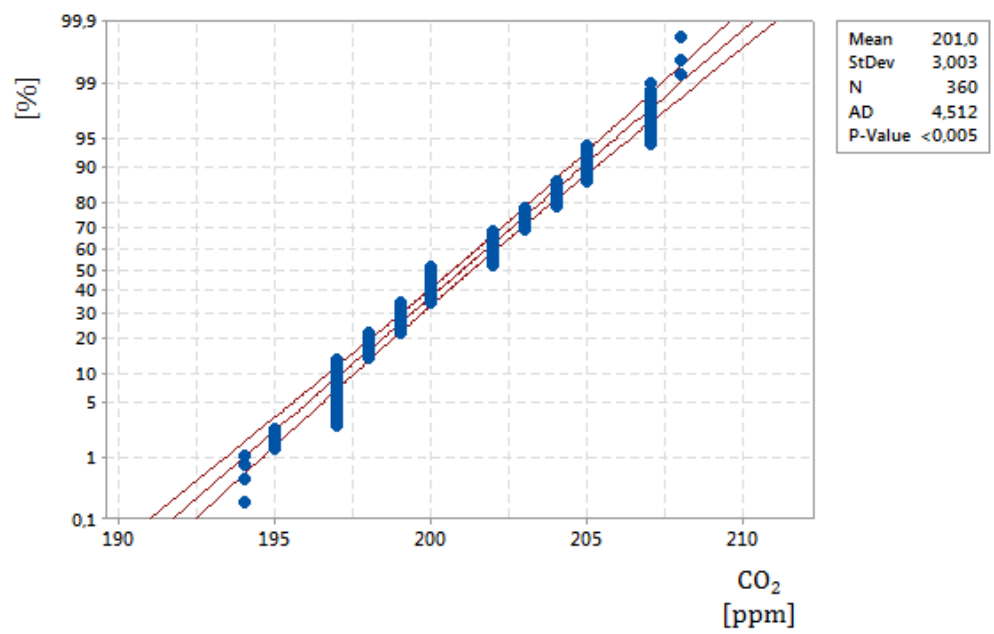

Fig. 3 Graphical test of normality for fundamental standard measurement results. Source: own research. 
Fig. 4 shows a run chart of the measurement process against the nominal value of fundamental standard $x_{w z}=200 p p m \pm 1 p p m \quad C_{2}$. Preliminary analysis of stability and ability of the measuring system to supervise the breathing gas production process to hyperbaric oxygen conditions ${ }^{44}$ was performed with the application of 1 MSA Procedure 45 [7]. As part of the procedure, the uncertainties of measurement have been estimated, the performance indicators of the measurement system have been calculated $C_{g}$ and $C_{g k}$ and the occurrence of bias has been estimated. According to the requirements [8] the set tolerance limits of the production process for $\mathrm{CO}_{2}$ are respectively $U S L=500 \mathrm{ppm}^{46}$ and $L S L=0 \mathrm{ppm}^{47}$. They are defined as critical for the quality control of the controlled process $\left(C T Q^{48}\right)$. The process lower limit set by the lower specification limit $L S L=0$ should be regarded as natural, since in any case the carbon dioxide content of the control sample, will take the value $C_{\mathrm{CO}_{2}} \geq 0$.

The production process breathing air, and the breathing mixture filtering and treatment sub-processes occurring in it, should ensure a content of standardised contaminants lower than the critical value ${ }^{49}$. The application of the above evaluation procedure of the measuring system is dictated by the necessity to make an initial evaluation of the automated measuring system before it is used to supervise the production line. The assessment will provide the basis for the qualification of the device to supervise the process and further conclusions for assessing the stability 50 of a measuring device over time.
To assess the ability of the measurement process to meet the critical quality requirements $C T Q$ indicators of the capacity of the measuring device have been applied $C_{g}{ }^{51}$ and $C_{g k}{ }^{52}$. When assessing the ability of a process to meet critical quality requirements $C T Q$ the actual indicators should be higher $C_{g}, C_{g k}>1,33^{53}$. Analysing the indicators gives the possibility to identify the occurrence of deterministic disturbances that cause instability of the measurement process. The scatter rate of the measuring system $C_{g}$ expressing the potential ability of the measuring device to meet critical quality requirements $C T Q$ has been calculated from the relationship: $C_{g}=\frac{k / 100 \cdot T}{6 \cdot s_{g}}$ where: $k \in[10 \div 20]$, $s_{g}-$ standard deviation of measurement results ${ }^{54}$, $T$ - process tolerance. The centring indicator $C_{g k}$ indicating the actual capacity of the process, taking into account its current centring and scatter has been calculated from the relationship: $C_{g k}=\frac{\left(\frac{k}{200} \cdot T\right)-\left|\bar{x}-x_{w z}\right|}{3 \cdot s_{g}}$, where $\bar{x}-$ the process mean value, $x_{w z}-$ the reference value of the standard. It follows that the indicators are related to the limits $k=0.1 \div$ $0.2 T=0.1 \div 0.2(U S L-L S L)$. In the case under consideration for $k=0.155$ calculated $C_{g}=5.55$ i $C_{g k}=5.45$. They therefore assume the values $C_{g}, C_{g k}>$ 1.33. Hence, the measuring device in question is capable and the variability of the measuring process is small in relation to the accepted tolerance limits. The value of the coefficient $C_{g}$ indicates that the total variability of the measuring device is 5.55 times within the range defined by the process $0.1 T$ tolerances, Fig. 5 .

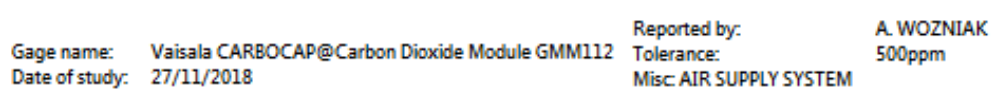

Run Chart of $\mathrm{CO} 2$
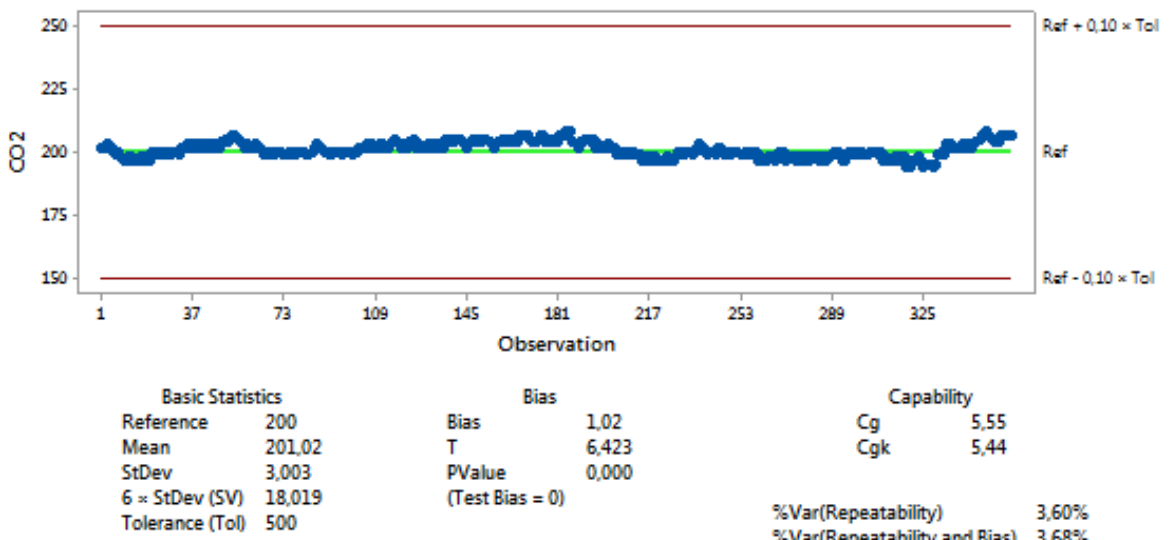

Fig. 4 Carbon dioxide measurement system (MSA) capability assessment procedure using fundamental standard measurement $\mathrm{CO}_{2}=200 \mathrm{ppm}$ and control lines $L C L=150$ and $U C L=250 \mathrm{ppm}$ of the supervised process at $(0,1 \cdot T)^{56}$. Source: own research. 
To identify the bias that occurred 57 for assessment of measurement method accuracy 58 a comparison of $\bar{x}$ empirical measurement data has been made with the value $x_{w z}$ of the standard ${ }^{59}$. The hypothesis $H_{0}$ : bias $=0$ has been verified against the alternative $H_{1}$ : bias $\neq 0$, where bias $=\bar{x}-x_{w z}$. The calculated value of the test statistics $t$ is greater than the than the critical value $t_{k r}$ corresponding to the materiality level $\alpha=0.05\left(t=6.423>t_{k r}=1.968\right), p-$ value $=0$ the hypothesis $H_{0}$ na should therefore be rejected in favour of an alternative $H_{1}$ considering that the measurement is burdened by the existence of a permanent statistically significant bias bias $=1.02 \mathrm{ppm}$, Fig. 4 . Usually, if there is a bias, it should be corrected by calibrating the measuring system.

The obtained measurement result error resulting from its systematic component is scant (bias $\approx 1 \mathrm{ppm}$ ) in relation to the defined process tolerances and the manufacturer's declared measurement variability of the system ${ }^{60}$. The occurring systematic impact can be omitted as it is equal to the resolving power ${ }^{61}$ of the measuring system. This is also confirmed by the comparison $\bar{x}$ with a reference value $x_{w z}$ taking into account the uncertainty values ${ }^{62}$ of their determination, fulfilment of relation $\quad\left|\bar{x}-x_{w z}\right|<2 \sqrt{u_{\bar{x}}^{2}+u^{2}{ }_{x_{w z}}}=1.02<1.16$ indicates that the obtained $\bar{x}$ is in accordance with the reference value $x_{w z}{ }^{63}$ [8].

The calculated percentage of variation for repeatability ${ }^{64}$ is $\% \operatorname{Var}(\operatorname{Rep})=3.60 \%$ Fig. 4 . It is determined by the value of the calculated capacity coefficient $C_{g}$ while the percentage of repeatability and bias $65 \% \operatorname{Var}($ Rep and Bias $)=3.68 \%$ results from the position coefficient $C_{g k}$.

Both of these values, from repeatability and bias, should not exceed $>15 \%{ }^{66}$. The values obtained are less than the critical value and it must therefore be assumed that the variability of the measuring instrument is small. A possible exceeding of the critical value suggests excessive measurement variability of the instrument. Such a situation may lead to the elimination of the device due to lack of sufficient repeatability and/or excessive impact of bias on the measurement performed. Therefore, a possible deterministic cause(s) of excessive variability must be identified, and the system calibrated and re-validated before allowing control measurements to be taken on the production line. If bias $\neq 0$ the probable causes of a phenomenon that may result from, for example, an error in the reference value, excessive wear and tear of the measuring instrument ${ }^{67}$ etc have to be sought.

Another cause may be incorrect execution of the calibration procedure or incorrect operation of the system by the operator68. The possibility of an incorrect instrument correction algorithm having been used should also be considered. The overriding aim of the conducted verification is to identify causes and disturbances of the measurement process to eliminate them and then restore the measurement capability. It is known that the differentiality of a measurement system should make it possible to identify 69 its variability and the special (specific) reasons that cause it. Distribution of measurement data in relation to the nominal value against the tolerance interval $T$ is shown in Fig. 5.

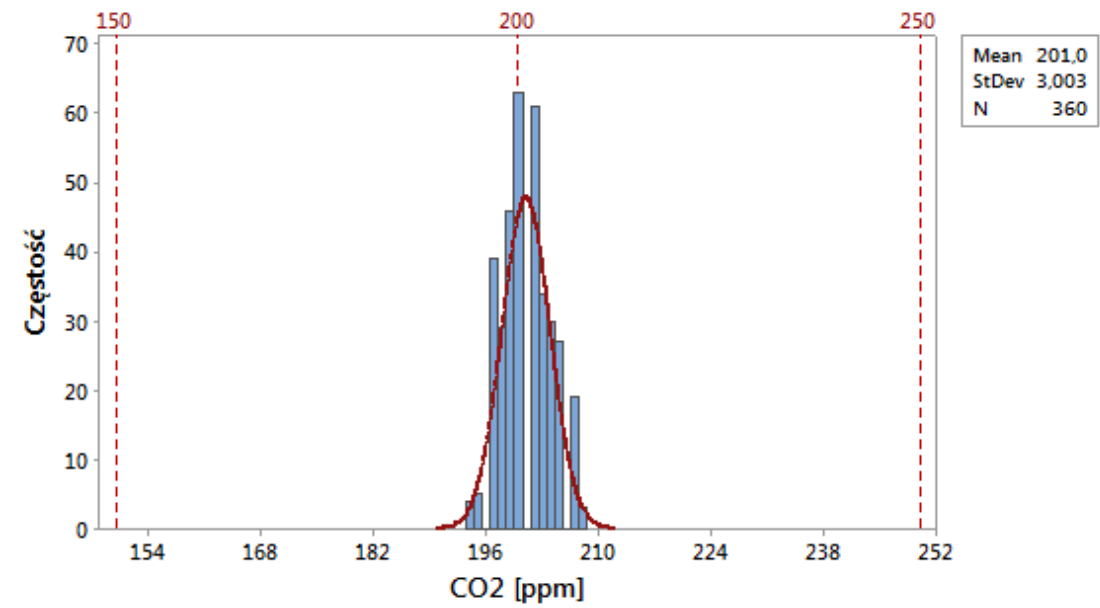

Fig. 5 Variability of the carbon dioxide measuring system against $(0.1 \cdot T)$ the process tolerance interval $\left(L C L=150, U C L=250 p p m, x_{w z}=\right.$ $200 \mathrm{ppm}, \bar{x}=201 \mathrm{ppm}$ ). Source: own research.

A check sheet can be developed for the measurement process as for the production process [6]. In case of online monitoring the sheet can be a control tool to assess the stability of the measurement process ${ }^{70}$ for the nominal value $x_{w z}=200 p^{71}$ and standard deviation $\sigma=3 p p m$ check sheet for single observations and moving range can be used for the analysis $I-M R$ Fig. 6 . The individual value sheet $I$ and moving range which can be used for the analysis $M R^{72}$ do not show points outside the fixed control lines $L C L^{73}$ and $U C L^{74}$. Despite trends indicating a periodical shift of the process and its change in position and the range relative to the centre line should be considered as stable and the influences result from the natural variability of the tested measuring system. 

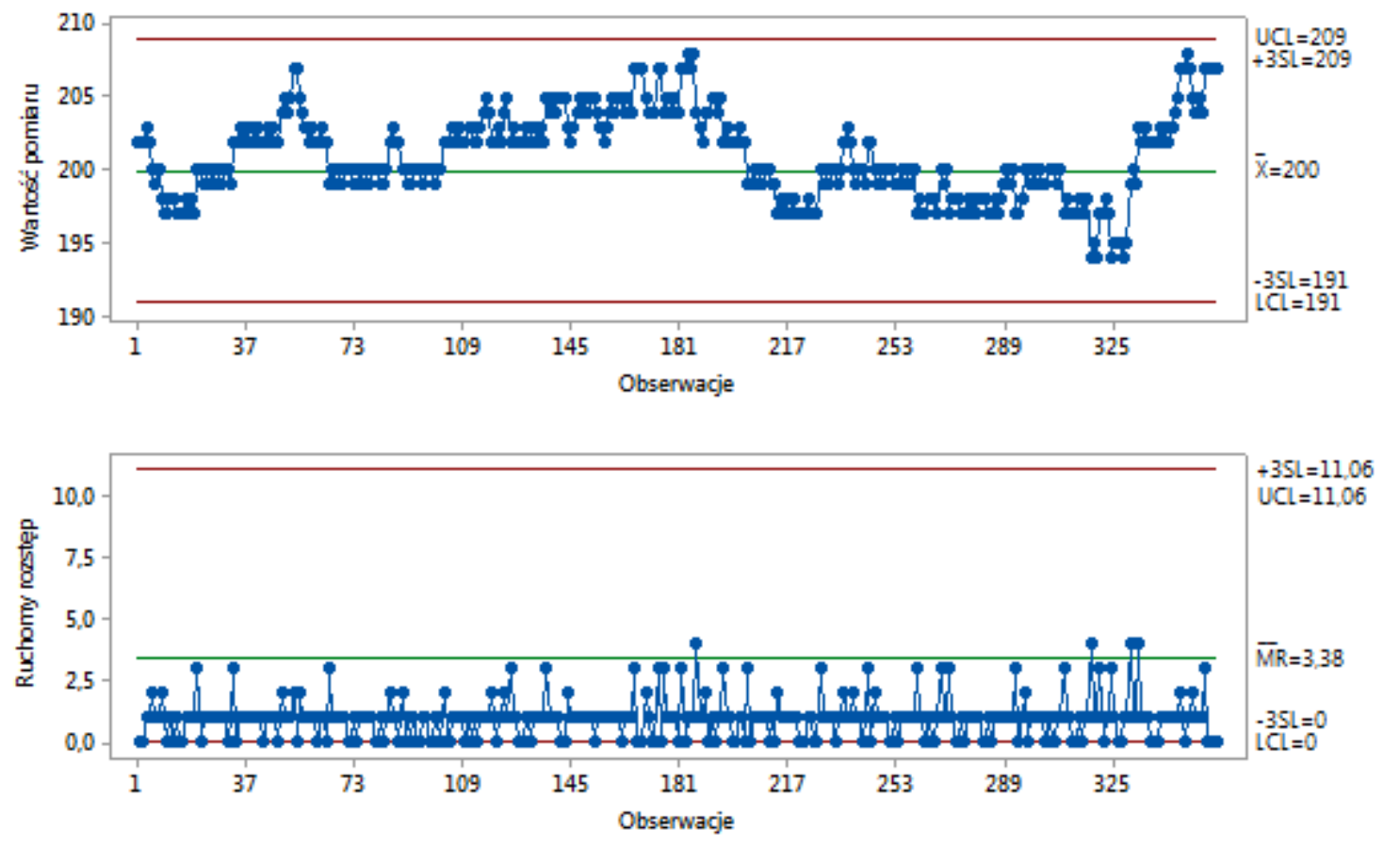

Fig. 6 Check sheet $I-M R$ for monitoring the stability of the measuring system. Source: own research.

With a view to a preliminary estimate of the bias for fundamental standard $\mathrm{CO}_{2}=200 \mathrm{ppm}$ To examine the linearity of indications and estimate the value of bias within the defined measuring range $(0-700 \mathrm{ppm})^{75}$ a test was carried out76 using three standards with contents respectively: $x_{w z 1}=0 p p m \mathrm{CO}_{2}, x_{w z 2}=$ $200 p p m \mathrm{CO}_{2}, x_{w z 3}=600 p^{2} \mathrm{CO}_{2}$.

A comparison has been made between the obtained mean values $\bar{x}$ of measurements with each reference value $x_{w z}$

To identify the differences between the occurring biases depending on the place of measurement within the measuring range of the measuring system, its linearity has been verified. A detailed analysis of the linearity of the measuring system with the estimation of the bias is shown 77 in Fig. 7. The linearity percentage for the measurement system is $4.4 \%$ the total process variability and the value of the mean bias is $7.9 \%$ from the mean process variability which corresponds to the measurement value $\overline{b l a s}=1,43 \mathrm{ppm}^{78}$.

In the limit values respectively $0 \div 600 \mathrm{ppm}$ a relatively large bias occurs from $-12,38 p^{79}$ to $14,87 \mathrm{ppm}^{80}$. The smallest bias value is observed for the $200 \mathrm{ppm}$ standard, $200 \mathrm{ppm}$, bias $=1.8 \mathrm{ppm}$. The coefficient of determination corresponding in this case to the square of the correlation coefficient Pearsona $r^{2}=$ $82,3 \%$. has been assumed as the linear dependence measure. Slope of a straight line 81 is 0.0435 . The regression line is described by the equation $y=-10.195+0.0435$. $x_{w z}$. The value $p-$ value $=0$ indicates the statistical significance of the slope 82 thus the observed linearity is statistically significant. 

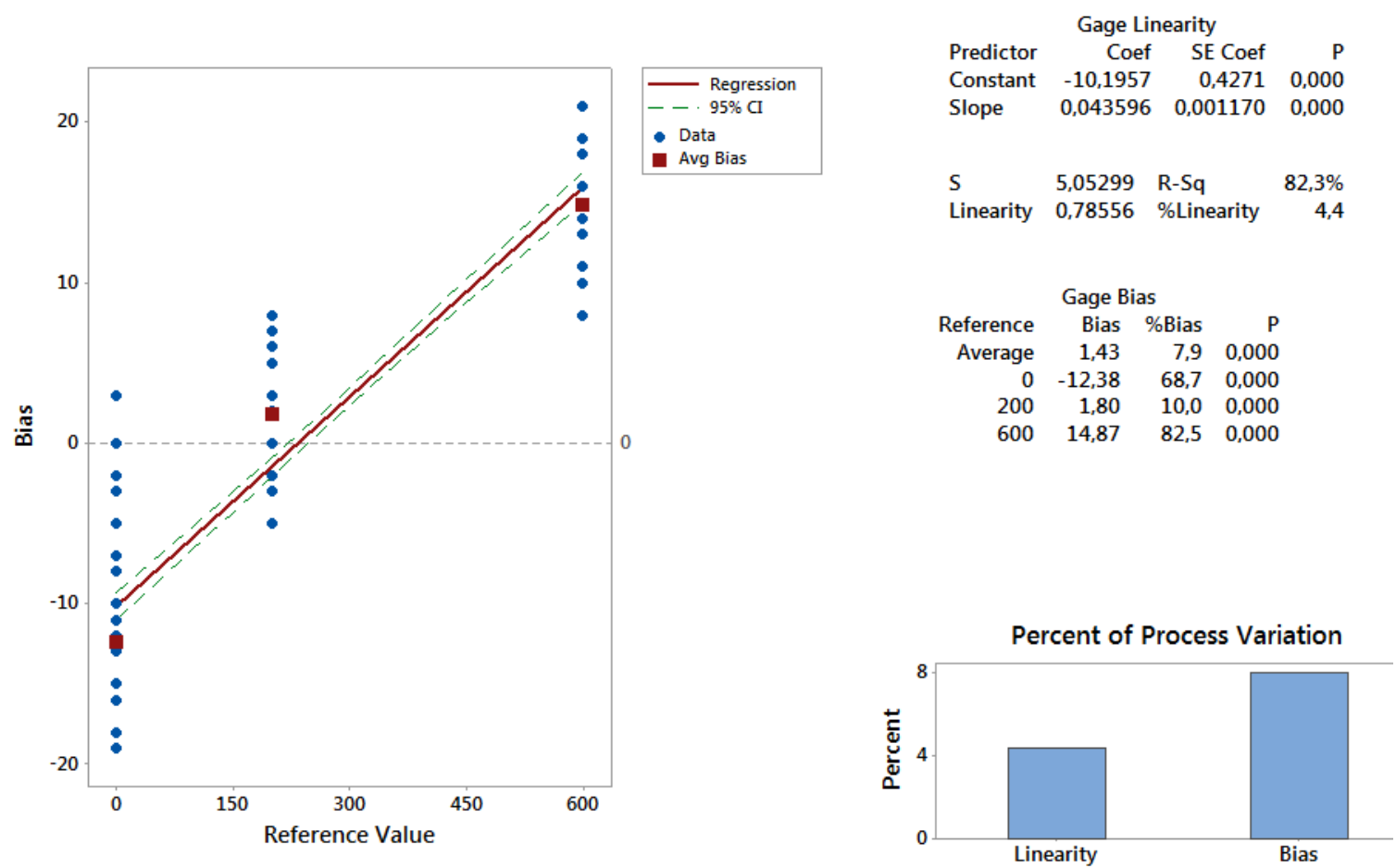

Fig. 7 The analysis of linearity and bias of the measuring system. Source: own research.

If the measuring system does not show significant linearity, it would have to be recalibrated to null bias by modifying the measuring system, software or both. If the occurring deviation cannot be adjusted to null biasburdened over the entire measuring range, the system can still be used for product/process control in a conscious manner.

\section{REPEATABILITY ASSESSMENT}

After estimating the correctness of the measuring system ${ }^{83}$ by assessing the bias occurrence and linearity, the variability of the measuring system has been estimated $\% G R R$ and the repeatability has been evaluated as a component of precision without the reproducibility 84 of the measuring system by means of one-factor variance analysis ANOVA of the crossed type ${ }^{85}$ [9]. The measurement system qualification has been performed against the set limits of the specification of the analysed process. It must be assumed that the supervised process must be followed by a suitable measuring system with proven metrological characteristics. The suitability of measuring systems for monitoring and improving processes is determined by their statistical properties. Therefore, for proper process control, the variability of the measuring system should be small compared to its overall variability ${ }^{86}$ and the measurement system should be under statistical control.

The repeatability analysis ${ }^{87}$ for the system has been performed on the basis of multiple measurements of reference values 88 for the adopted width of the specification range of the supervised process $(T=0 \div$ $500 \mathrm{pmm}$ ). The total variability is the sum $T V^{89} \mathrm{PV}+$ $G R R$, where $P V$ - the process variability and $G R R$ - is the variability that comes from the measurement system.

Due to the automated system, the hypothesis $H_{0}$ - does not exist and the difference between the operators will not be tested (as there is no operator influence on the measurement result). The hypothesis that there is $H_{0}-$ no difference between the parts will be verified. Fig. 8 shows the results of the ANOVA singlefactor variance analysis. 


\section{One-Way ANOVA Table}

\begin{tabular}{lrrrr|r|} 
Source & DF & SS & MS & F & P \\
PART & 2 & 20331415 & 10165708 & 508382 & 0,000 \\
Repeatability & 297 & 5939 & 20 & & \\
Total & 299 & 20337354 & & \\
& \\
a to remove interaction term $=0,05$ &
\end{tabular}

\section{Gage R\&R}

$\begin{array}{lrr}\text { Source } & \text { VarComp } & \begin{array}{r}\text { sContribution } \\ \text { (of VarComp) }\end{array} \\ \text { Total Gage RaR } & 20 & 0,02 \\ \quad \text { Repeatability } & 20 & 0,02 \\ \text { Part-To-Part } & 101657 & 99,98 \\ \text { Total Variation } & 101677 & 100,00\end{array}$

Process tolerance $=500$

\begin{tabular}{|c|c|c|c|c|}
\hline & \\
\hline Source & StdDev (SD) & 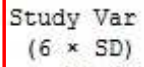 & $\begin{array}{r}\text { \$Study Var } \\
\text { (\%5V) }\end{array}$ & $\begin{array}{l}\text { \$Tolerance } \\
\text { (SV/Toler) }\end{array}$ \\
\hline Total Gage RaR & 4,472 & 26,83 & 1,40 & 5,37 \\
\hline Repeatability & 4,472 & 26,83 & 1,40 & 5,37 \\
\hline Part-To-Part & 318,837 & 1913,02 & 99,99 & 382,60 \\
\hline Total Variation & 318,868 & 1913,21 & 100,00 & 382,64 \\
\hline
\end{tabular}

Fig. 8 Variability analysis ANOVA of the measurement process against the tolerance interval $T=0 \div 500 p p m$ of the supervised process for $n=$ 100 measurements and 3 parts without the operator. Source: own research.

The analysis for the adopted $\alpha=0,05$ one indicates that, in view of the value obtained $p-$ value $=$ $0<0.05$ of the tested hypothesis $H_{0}$ should be rejected and it should be assumed that, against the background of the variability of the measurement system analysed, variability is visible within a defined range of specifications (i.e. there is a significant difference between the parts ${ }^{90}$ ). This means that for reasons of repeatability 1 we are able to identify the variability of the supervised process using a measuring system. Taking into account the percentage share of individual variability to total variability from the obtained table ANOVA Fig. 8 it shows ${ }^{92}$ that the share of variability coming from the part ${ }^{93}$ is much higher than the total variability of the measurement system $^{94}$.

It follows that almost all the observed variability comes from the differences between the parts (standards) and not from the measuring system.

As is known, the calculated variability of the measurement system $G R R=26.83$ in the case under consideration comes entirely from the repeatability component. The measurement system variability GRR should be referred to the total variability $T V=1913.21$ meeting the adequacy condition $\frac{G R R}{T V}<10 \%$ as calculated $\% S V(\% G R R)=\frac{G R R}{T V} \cdot 100 \%=1.4 \%<10 \%$.

We therefore conclude that the system, due to its repeatability, is suitable without any limitations to supervise the process. With regard to product surveillance for the declared specification limits $T=0 \div 500 \mathrm{ppm}$ the measuring device can be used without restrictions as it is: $S V / T=\frac{G R R}{T} \cdot 100 \%=5.37 \%<10 \%$. The differentiation of the measuring system should be seen as a number of $\begin{array}{lll}\text { distinguishable } \quad \text { categories } n d c^{95} & =\end{array}$ $\sqrt{2 \cdot\left[\left(\frac{100}{\% G R R}\right)^{2}-1\right]} \approx 10096 \gg 14$. The measuring system meets the adequacy condition ${ }^{97}$ as it differentiates about 100 "statuses" within the specification 98 while informing us how many times the variation of the measuring system is less than the variation of the process.

To determine whether the measuring system is capable, an alternative criterion [10] on a coefficient of precision ${ }^{99}$ to tolerance $\left(P T R^{100}\right)$. For the tested measuring system $P T R=\frac{k \cdot \sqrt{\sigma^{2} m^{101}}}{(U S L-L S L)}=\frac{6 \cdot 5102}{(U S L-L S L)}=0.053$, for $k=6103$.

Thus as $P T R=0.053<0.1$ the system should be considered fit as the following application rule is recommended PTR:

- $\quad P T R<0,1$ : the measuring system is fit for purpose,

- $\quad 0.1<P T R<0.3$ : the measurement system may be fit for the purpose, depending on factors such as process capability and misclassification costs,

- $\quad P T R>0.3$ : the measuring system is not fit for purpose [10].

It should be noted that $P T R$ does not always give a correct estimate of how well the measuring system works for the process under analysis. This is because the process of high capacity can tolerate a measurement system with a higher value of the coefficient PTR [10]. For this reason, the capacity of a measuring system is often determined by the function of a coefficient $\sigma^{2}{ }_{r}=\frac{\sigma^{2} p_{1}}{\sigma^{2}{ }_{m}} 104$ that determines the ratio of variance of a measuring system to process variance. The signal-to-noise ratio $(S N R)^{105}$ is a function of the coefficient $\sigma^{2}{ }_{r}$, defined as: $S N R=\sqrt{2 \cdot \sigma^{2}{ }_{r}}$. SNR is defined as the number of separate categories ${ }^{106}$ that can be reliably distinguished by the measuring system. It is recommended that the indicator 
values take the values $\geq 5$. The value $S N R \leq 2$ indicates a measurement made by a system that does not have any analytical value [10].

\section{STABILITY ASSESSMENT OVER TIME}

Stability of the system to keep the metrological characteristics constant over time has been assessed on the basis of periodic reference value measurements 107 . The stability of the measuring system is a measure of the difference between the mean value of the results of identical series of measurements $\bar{x}$ to the nominal value of fundamental standard $x_{w z}$. Measurements were made under the same conditions, at specified intervals [5]. The smaller the differences identified $\Delta x_{w z}=x_{w z}-\bar{x}$ over time, the more stable the system will be. The system has been tested by periodically measuring carbon dioxide fundamental standard $x_{w z}=200 \pm 1 p p m$. The stability declared by the supplier for the measurement sensor over a period of 5 years is $\Delta \pm 5 \%$ its measurement range of the sensor $Z$. Changes are therefore to be expected in the scope $\Delta x_{w z} \pm 100 p p m$. As mentioned for the purpose of the supervised production process, the limits of the specification have been taken as the limits $U S L=$ $250 p p m, L S L=150 p p m\left(x_{w z} \pm 50 p p m=0.1 T\right)$. These limits are similar to the supplier's declared accuracy 108 $\Delta x_{w z} \leq 44 p p m$ for reading $x_{w z} C_{2}=200 \pm 1 p p m$ and measuring range $Z=0 \div 2000 \mathrm{ppm}$.

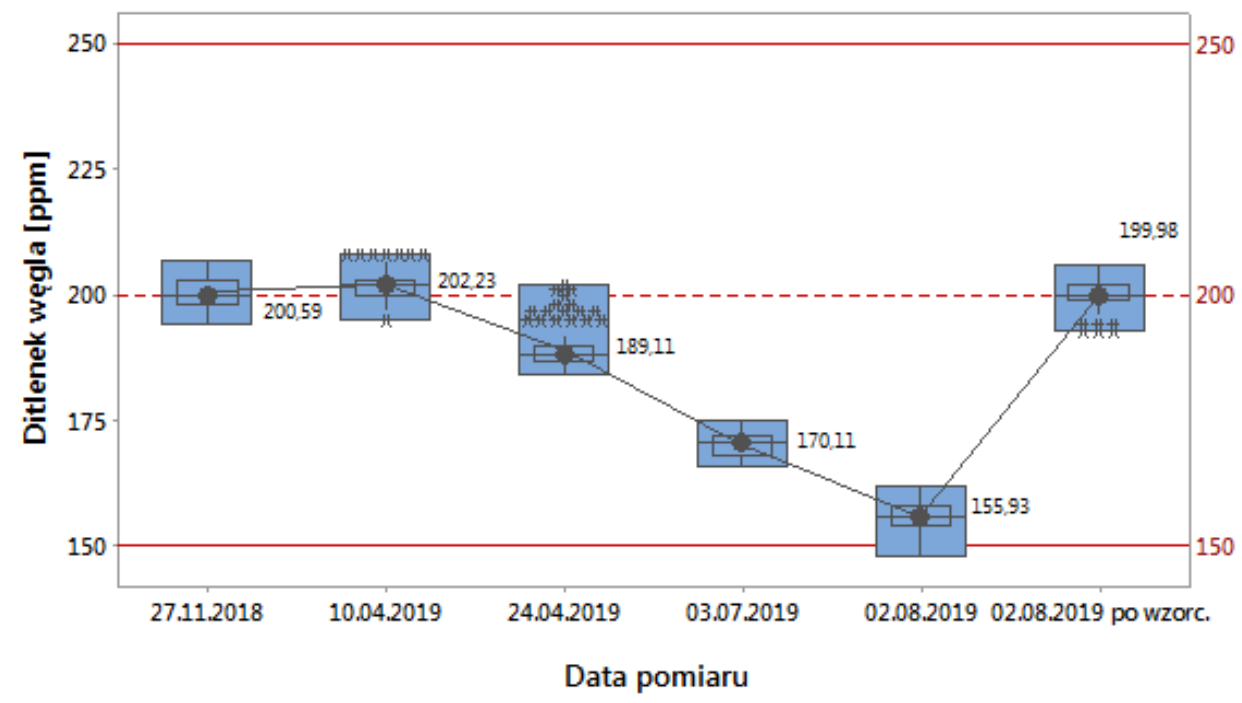

Fig. 9 Mean $\bar{x} \pm \Delta x(1-\alpha=0.95)$ the measurement of carbon dioxide fundamental standard $x_{w z}=200 \pm 1 p p m$ over time. Source: own research.

The tests showed that the lower specification limit was exceeded in the ninth month of operation Fig. 9. For this reason, the measuring device was recalibrated to eliminate the identified bias in the measurement Fig. 10. Calibration was made on the basis of measurements of voltage $[\mathrm{mV}]$ against 2 carbon dioxide fundamental standards. The calibration curve has been made Fig. 11. The conformity of the measurement result with the material of the report after calibration is shown in Fig. 9. 


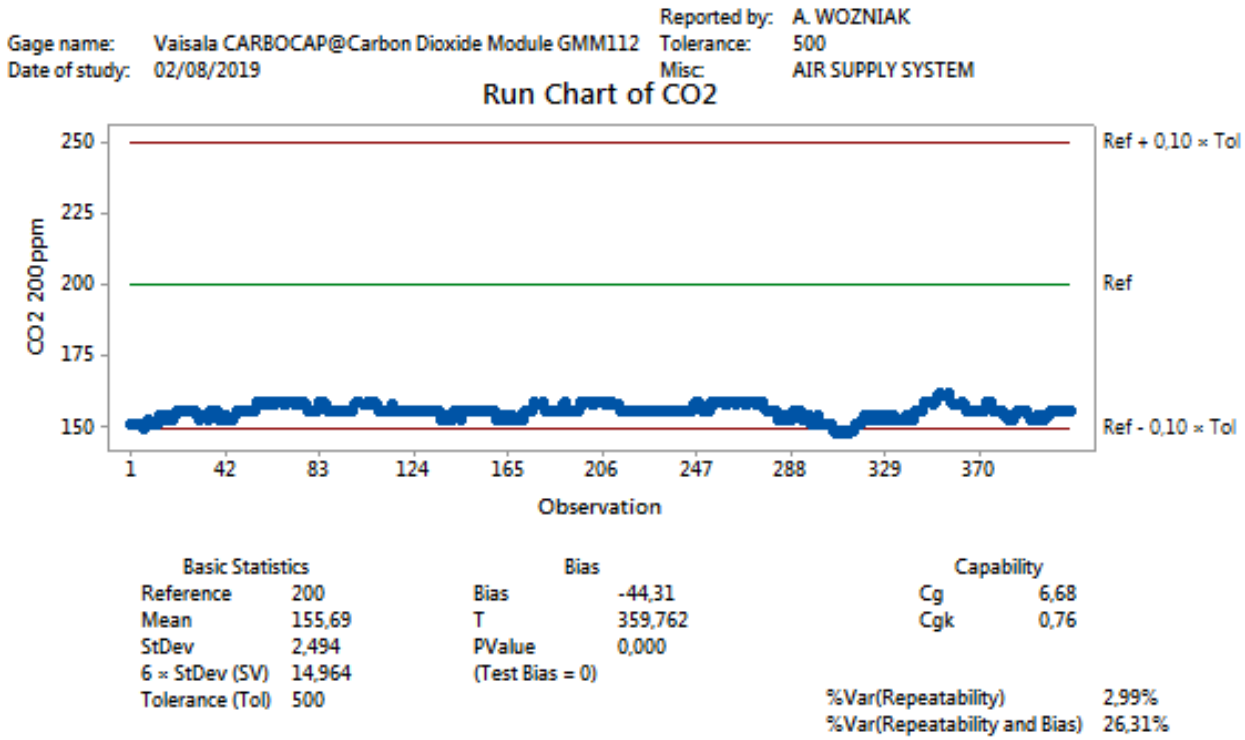

Fig. 10 Procedure for assessing the capability of a carbon dioxide measurement systems before calibration for fundamental standard $x_{w z}=$ $200 \mathrm{pm}$ and tolerance limits $L S L=150, U S L=250 \mathrm{ppm}$. Source: own research.

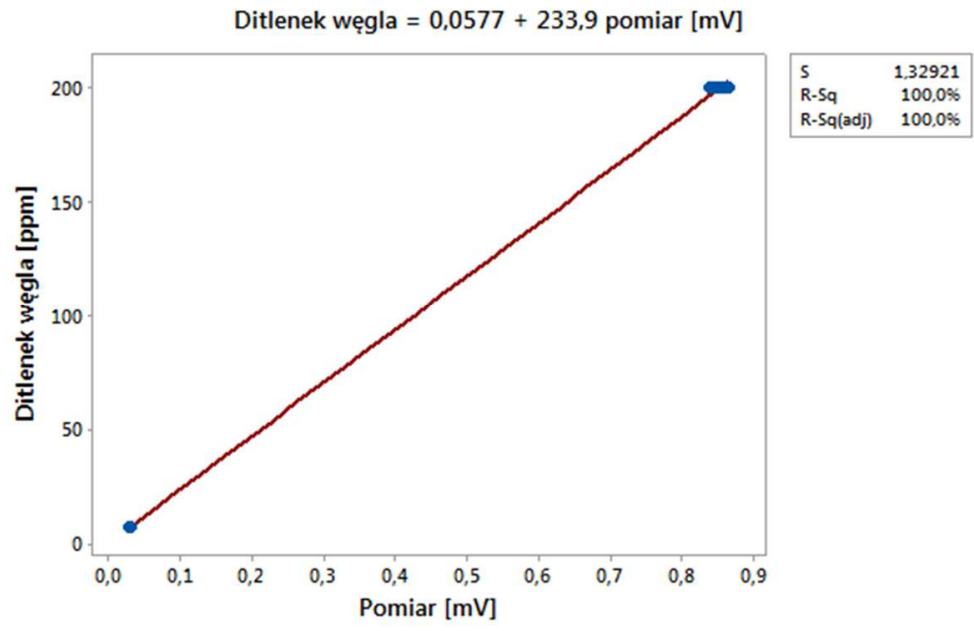

Fig. 11 Calibration curve for the determination of carbon dioxide based on measurements of carbon dioxide fundamental standards $x_{w z 1}=200 p p m$ and $x_{w z 2}=7 p p m$. Source: own research.

The changes in the stability of the measuring system, identified during the time of change in the stability of the measuring system due to the nature of the supervised process and correct conclusions about its variability, indicate the necessity to perform metrological control of the measuring system not less than every 5 months of the device's operation.

\section{ConClusions}

The measurement accuracy of the considered measuring device under proper metrological supervision is significantly higher than that declared by the manufacturer ${ }^{109}$. It is sufficient for the initial qualification of the measuring device. The determined components of correctness and precision ${ }^{110}$ indicate the suitability of the system to supervise the breathing air production process. The obtained results of the initial assessment of the carbon dioxide measuring device and the tests performed earlier [1] are the basis for further recommendations concerning the continuation of supervision over the process of obtaining breathing air.

Due to the increasing carbon dioxide contamination of the ambient air111 and the observed technological limitations 112 , the applied filtering arrangement in the responsible systems should be considered complementary to the 3 monthly laboratory breathing air periodic monitoring, incorporating operation testing ${ }^{113}$, by means of indicator systems in the online mode. In the specification $S Z R P$ special attention should be paid to high-pressure systems used for the production of breathing mixtures, supply of life support systems for submarines and rescue vessels and mobile container power systems $P Z Z P^{114}[11]$. This is important during their intensive operation, especially at a distance from supply facilities ${ }^{115}$. Securing their operation in the event of a sudden loss of supervised process capability can prevent contamination of distribution systems and the unknowing use of contaminated breathing agents for underwater work 116 or ventilation $O P^{117}$. When using indicator systems, they should be subject to systematic metrological surveillance 
and periodically tested during production using the methods MSA. Before being used under operating conditions, the safety sensory systems shall be subjected to metrological evaluation and verification tests ${ }^{118}$ for compliance with the declared technical parameters.

In case of implementation of indicator systems in $S Z R P$, supplementary training should be provided periodically for the modified SOP. Monitoring systems online are an ideal tool for the verification of the production process, effectively preventing the materialisation of process hazards by eliminating the occurrence of defects at the product production stage. The use of sensory indicator systems to monitor the analysed process:

- reduces the probability of shutting down compression systems- improving the machine duty factor;

- minimises the risk of stopping the production and delivery process for the customer;

- reduces the costs arising from the upgrade and rearming of the compression and filtration system;

- eliminates costly cleaning of dirty distribution systems;

- $\quad$ prevents contamination of the breathing mixtures;

- $\quad$ reduces the cost of laboratory retesting ${ }^{119}$;

- leads to a reduction in the stock of filter elements $^{120}$;

reduces storage $\operatorname{costs}^{121}$;

eliminates operator errors and mistakes;

provides ongoing diagnostic information and identification of process disturbances;

signals the failure of filtration systems (e.g. in case of sudden loss of sorption properties), and

allows for constant verification of the declared operating parameters of the breathing air treatment systems (protective operation time, amount of filtered atmospheric air, etc.).
It is thus an ideal complement to laboratory periodic analyses and a reliable source of information for the user. When introducing compression systems and filtration systems to be used in the implementation of new projects, investments and construction of new ships ${ }^{122}$ at the design stage should be aimed at unification and application of redundant measurement systems together with extended indicator systems of proven effectiveness ${ }^{123}$.

Preliminary analysis and performed in $K T P P A M W$ technology demonstrator tests confirm the possibility of meeting the requirements [13] $M W R P^{124}$ and indicate that there are opportunities to use their own competitive indicator solutions of measuring systems with parameters not inferior and functional solutions better than those currently offered on the market. The benchmarking analysis confirms the strengths of the designed system in relation to competitive products. Consideration should therefore be given to the implementation of the proposed systems in MWRP, in particular where it appears necessary for the safety of underwater works.

By publishing this material, I would like to cordially thank Professor of the Polish Naval Academy - dr hab. inż Ryszard KŁOS, for the possibility of conducting research on the quality of breathing agents within the framework of scientific work directed by: Tulipan IV Contract No: DOBR-BI08/09/01/2016, titled.: "Projektowanie dekompresji dla nurkowań MCM/EOD II" (Designing decompressions for diving) and to thank dr inż. Andrzej CZARSKI for his support and assistance at the test implementation stage.

\section{REFERENCES}

Woźniak A Analysis of the process of obtaining breathing gas for hyperbaric purposes. Gdynia: PTMiTH, 2017. ISBN 978-83-938-322-4-8,

-. Analysis of the process of obtaining breathing gas for hyperbaric purposes. Polish Hyperbaric Research. 1, 2018, Vol. 62, pp. 7-32;

Sałaciński T. Quality engineering in production techniques. Warszawa : Oficyna wydawnicza Politechniki Warszawskiej, 2016. ISBN 978-83-7814616-2;

4. Woźniak A. Evaluation of the impact of breathing air contamination on safe performance of hyperbatic exposure. IV. Gdynia : Zeszyty Naukowe AMW, 2016. pp. 101-111. ISSN 0860-889X;

5. Sałaciński T. SPC. Statistical control of production processes. Warszawa : Oficyna Wydawnicza Politechniki Warszawskiej, 2016;

6. Gerber A. Statistical process control - improving quality with the Statistica package. Kraków : Stat Soft, 2000. ISBN 83-912346-2-2;

7. Automotive Industry Action Group. Measurement System Analysis Reference Manual 4th Edition. brak miejsca : Chrysler Group LLC, Ford Motor Company, and General Motors, 2010;

8. NO-07-A005:2010. Diving for military purposes. Breathing mixtures. Classification, requirements and research. Warszawa : WCNJK

9. Namieśnik J Konieczka P, Zygmunt B, Bulska E. Assessment and quality control of analytical measurement results. I. Warszawa : Wydawnictwo WNT, 2017. ISBN 978-83-01-19444-4;

10. Czarski A. Statistical process control SPC with analysis of MSA measuring systems. Kraków : TQMSoft, 2017. Tom Materiały szkoleniowe;

11. Burdick R.K. Borrow C.M., Montgomery D.C. Design and Analysis of Gauge R\&R Studies: Making Decisions with Confidence Intervals in Random and Mixed ANOVA Models. Philadelphia : Society for Industrial and Applied Mathematics, 2005. ISBN 0-89871-588-1;

12. Woźniak A. Concept for medical oxygen and breathing air supply system of KOBBEN type. Gdynia : DMW, 2003;

13. ADivP-04 (A)(1):2013. Diving Gas Quality (STANAG 1458). Brussels : Nato Standarization Office;

14. PN-EN-12021:2014-08. Breathing equipment. Compressed gases for breathing apparatuses.

dr inż. Arkadiusz Woźniak

Katedra Technologii Prac Podwodnych

Akademia Marynarki Wojennej w Gdyni

ul. Śmidowicza 69

81-103 Gdynia

tel. 261262746

ar.wozniak@amw.gdynia.pl 
${ }^{1}$ Critical to Quality,

2 e.g. measuring set $A C G$ Analox or other

${ }^{3}$ CCS - Carbon Dioxide Control System,

4 Department of Underwater Works Technology of the Polish Naval Academy,

5 experimental deep-water hyperbaric system,

${ }^{6}$ Measurement System Analysis,

7 Statistical Process Control,

8 the quality measure used in the Sigma Quality Level corresponding to, in this case, the process/cycle performance $\mathrm{Y}_{\mathrm{Tp}}>90,3 \%$ (throughput yield) defects per million opportunities ${ }^{1}$ DPMO $<96800$,

9 ambient air intake

10 resulting from the NO-07-A005:2010 requirements and Stanag 1458,

11 e.g. a measuring set $A C G$ Analox or other,

12 FMEA (Failure Mode and Effects Analysis),

13 such as poka-yoke,

14 implementing elements,

${ }^{15}$ capacity means that the measuring system meets the following quality characteristics: resolving power, uncertainty, accuracy, repeatability, reproducibility, repeatability and stability over time,

16 measurement processes must be metrologically proven,

17 this should be regulated, i.e. stable, centred and under control if the critical quality requirements of CTQ resulting from NO-07-A005:2010 are met,

18 e.g. SECURUS,

${ }^{19}$ carbon dioxide content in the atmosphere of the breathing air intake for compression systems. So far, there has been no permanent monitoring of air parameters either in the air intake or at the outlet of the filtration system,

${ }^{20}$ carbon dioxide content behind the breathing air treatment system at the entry to the breathing mixture distribution system,

21 based on previous experience of the changes $S O P$ recommending the use of indicator systems for performance measurements,

22 by means of periodical tests performed in line with GLP at the physiochemical laboratory of breathing gases in a period of not less than three months with the planned operation of the system during $\tau \leq 50$ working hours. It has been confirmed that a quarterly data collection system is sufficient to monitor the breathing air production process if the operation of the equipment is periodic and the total compressor operating time is $t \leq 50$ hours,

${ }^{23}$ damage to compression systems and consequent contamination of distribution systems have been observed,

24 the use of the system for breathing air not only makes it impossible to use it, but also makes it necessary to prepare these systems for oxygen conditions again at a high cost,

25 primarily lubricants and oil vapours,

26 in line with $S O P$,

wykazano przekroczenia granic tolerancji nadzorowanego procesu w zakresie przekroczenia zanieczyszczeń krytycznych w zakresie ditlenku węgla,

27 the executive element has three operation statuses providing information about the quality of filter work, and in event of the allowed level of saturation of the filter element being exceeded, the supply compressor is automatically immobilised, in order to prevent certain contaminants in the breathing air being exceeded. During the tests, despite the correct system signaling, it was shown that the tolerance limits of the supervised process were exceeded in the scope of exceeding critical impurities in the scope of carbon dioxide,

${ }^{28}$ context is understood here as the system environment, i.e. the system superior to the breathing air system,

29 due to their metrological features,

30 to obtain confirmation that the uncertainty of the measurement result is acceptable from the point of view of the supervised process and to determine the influence of other external factors including environmental conditions on the uncertainty of the result,

${ }^{31}$ except for starting the measuring system before the compression system is operated,

32 the use of check sheets will allow to monitor the process course and to react faster to the potential occurrence of deviations, thus allowing to predict the occurrence of potential threats affecting the process deregulation,

${ }^{33}$ assessment of the short- and long-term capacity of the production process,

34 modified to obtain the best possible system response for the product,

${ }^{35}$ Carbon Dioxide Control System,

${ }^{36}$ experimental deep-water hyperbaric system,

37 department of Underwater Works Technology of the Polish Naval Academy in Gdynia,

38 vaisala CARBOCAP@Carbon Dioxide Module GMM112,

${ }^{39}$ gross error, mistake,

40 indicates that the resulting measurement value $x_{\min }=194 \mathrm{ppm}$ is 2.34 standard deviation less than $\bar{x}$

41 at the materiality level $\alpha=0,05$ no outlier measurements have been identified, the measurements come from the same population,

42 measurement points focus around a straight-line distribution testing is based on $A-D$ (Anderson - Darling Test),

${ }^{43}$ grouped together,

44 in terms of critical carbon dioxide content in the breathing air for divers according to NO-07-A005, STANAG 1458 (ADivP-04), PN-EN 12021,

45 MSA - Measurement System Analysis,

46 USL - Upper Specification Limit,

${ }^{47}$ LSL - Lower Specification Limit,

${ }^{48} \mathrm{CTQ}$ - Critical to Quality,

49 dichotomous variable: meets/does not meet,

50 the ability to maintain metrological characteristics,

51 indicating the capabilities of the measuring system for reasons of precision,

52 indicating the capabilities of the measuring system for precision and correctness,

53 in processes it is recommended, if possible, that the value of the index is $C_{p k}>1,33$. In companies for which the quality of the product is a priority, such as GM or Ford, the value of capacity indexes is assumed to be at least $C_{p}, C_{p k}>1,67$,

54 the value of $5.15 s_{g}$ instead of 6 is also sometimes assumed as $99 \%$ of all measurement results should be within this range,

55 due to the validity of the characteristics $k=0.1$ was assumed for calculations

${ }^{56}$ the prerequisite for the suitability of a system for measuring a feature with a tolerance of $T$ is the fulfilment of the condition $u \leq(0.1 \cdot T)$ [5],

57 verification of the systematic and change component for measurement error,

58 the degree of the measurement result conformity with the actual measured value,

59 of the certified reference material,

60 for the Reading $x_{w z}=200 \mathrm{ppm}$, the permissible measurement error $\Delta x_{w z} \leq 44 \mathrm{ppm}$ under defined environmental conditions (temperature, relative humidity and atmospheric pressure),

61 the resolving power of the measuring system should be within $2-5 \%$ the tolerance of the feature [5],

62 for the calculation the uncertainty of the reference value $x_{w z}=200 \pm 1 \mathrm{ppm}$ (dla $k=2$ ) is equal to the expanded uncertainty divided by the coverage factor: $\frac{U}{k}=$

$\frac{1}{2}=0,5 p p m$. Uncertainty $\bar{x}=201,02 \pm 0,3 p p m$,

${ }_{63}^{2}$ it should be noted that the conclusion is different from the test application $t$-Studenta because the uncertainty value was not taken into account,

64. \% Var (Repeatability),

$65 \% \operatorname{Var}$ (Repeatability and Bias)

$66 \% \operatorname{Var}($ Rep $), \% \operatorname{Var}($ Rep and Bias $)=15 \%$ corresponds to the value of the capacity coefficients for the measuring system $C_{g}, C_{g k}=1,33$,

67 in such a case, it should be suggested to change the existing system maintenance schedule,

68 in this case, the instructions for measurement should be revised,

69 from the point of view of the supervised process, 
70 the sheet may be developed by design or stabilisation method, based on a series of at least $n>30$ measurements before calculating and plotting the control limits and the central line. After eliminating the deterministic causes of the signals of deregulation and process stabilisation, the control limits should be recalculated,

71 the set target value of the measurement process corresponding to the value of the standard,

72 movable range - absolute value from the difference between two consecutive measurements,

${ }_{73}$ LCL- Lower Control Limit,

${ }^{74}$ UCL- Upper Control Limit,

75 the measuring range $0-2000 p p m$ for the analysed measuring system the limit $0-700$ ppm corresponds to the observed values of the measurement corresponding to $\mathrm{CO}_{2}$ the atmospheric air content

76 under the same measurement conditions,

77 the data has been randomised by selecting a series $n=100$ of measurement results for each standard,

78 many times less than the error declared by the manufacturer,

79 for the standard 0 ppm $\mathrm{CO}_{2}$

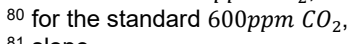

81 slope,

82 the slope $a=0,0435$ is significantly different from null ( $p$-value $=0$ ), the hypothesis being tested $H_{0}: a=0$ is rejected in favour of the alternative $H_{1}: a \neq$ 0 ,

${ }^{83}$ without assessing long-term stability

${ }^{84}$ due to the fact that the measurements are performed by an automated system, the operator has no influence on the measurement performed and therefore on the range of the measurement system

85 crossed, i.e. it is possible to take several measurements on one part (fundamental standard),

86 in both cases $<10 \%$

87 the conditions of standard distribution, equal variance and randomisation of data have been met,

${ }^{88}$ covering the variability range of the supervised process

${ }^{89} \mathrm{TV}$ - total variation,

${ }^{90}$ standards,

91 reproducibility is not considered,

92 in the column\%Contribution,

${ }^{93}$ part to part,

94 total gage R\&R

${ }^{95}$ number of distinct categories,

96 the system therefore has 100 categories statistically distinguishable,

${ }^{97} n d c \geq 14$ system fit, $n d c=4-13$ conditionally fit, $n d c \leq 3$ unfit,

98 minimum 10

99 of range is required,

100 precision to tolerance,

101 the measuring system variance (total gage GRR) $\sigma^{2}{ }_{m}$

102 where $6 \cdot s=G R R$

103 optionally $k=5,15$

104 process variation $\sigma^{2}$,

105 SNR - signal-to-noise ratio,

106 indicates how many times the variability of the measurement system is less than the process variability,

107 from the central zone of the variation range of the controlled process,

108 taking into account repeatability, non-linearity and calibration uncertainty,

109 amounting to $\pm 2 \%$ of the reading range $+2 \%$ including repeatability, non-linearity of measurements and calibration uncertainties,

110 except for reproducibility due to an automated system without the participation of an operator

111 in line with the research: Trends in atmospheric Carbon Dioxide - Global Monitoring Division of National Oceanic and Atmospheric Administration,

112 they will be the subject of a separate publication,

113 by using selected indicator systems,

114 portable Air Supply Sets has been implemented in the Polish Navy in the years 2003-2007 under Project A. WOŹNIAK "System zaopatrywania tlenem medycznym i powietrzem oddechowym okrętu podwodnego typu KOBBEN" (Medical oxygen and breathing air supply system for submarine KOBBEN) Reg. 2/2003/R/DMW. The producer of the first piece of the serial production for MWRP, PHU "AQUATICUS",

115 restricted access to the physiochemical laboratory, long stay of the ship at sea,

116 including saturated and in great depths,

${ }_{117} O P$ - submarine,

118 e.g. within the scope of operation tests of individual pieces of equipment in a specialised laboratory of the Polish Armed Forces,

119 Reanalysis,

120 the production problem compensation by over-stocking the filter elements,

121 due to the monitoring online observation of trends, there is a potential possibility of supplying according to the principle JIT - just in time,

122 e.g. project ships"KORMORAN" and "RATOWNIK",

123 despite the manufacturer's declaration, systems available on the market of dubious quality not meeting customer requirements have been identified,

124 QFD - Quality Function Deployment (of ten called House of Quality) for CCS. 